This item was submitted to Loughborough's Research Repository by the author.

Items in Figshare are protected by copyright, with all rights reserved, unless otherwise indicated.

\title{
Optical investigation on the ability of a cordierite substrate mixing device to combat deposits in SCR dosing systems
}

PLEASE CITE THE PUBLISHED VERSION

http://dx.doi.org/10.4271/2015-01-1039

PUBLISHER

(C) SAE International

VERSION

VoR (Version of Record)

LICENCE

CC BY-NC-ND 4.0

\section{REPOSITORY RECORD}

Lockyer, Thomas O., Benjamin A. Reid, Graham K. Hargrave, Paul D. Gaynor, and Jonathan Wilson. 2019. "Optical Investigation on the Ability of a Cordierite Substrate Mixing Device to Combat Deposits in SCR Dosing Systems". figshare. https://hdl.handle.net/2134/23256. 


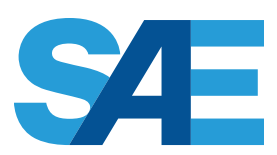

\section{Optical Investigation on the Ability of a Cordierite Substrate Mixing Device to Combat Deposits in SCR Dosing Systems}

\section{Thomas Lockyer, Benjamin Reid, Graham Hargrave, Paul Gaynor, and Jonathan Wilson}

Loughborough University

CITATION: Lockyer, T., Reid, B., Hargrave, G., Gaynor, P. et al., "Optical Investigation on the Ability of a Cordierite Substrate

Mixing Device to Combat Deposits in SCR Dosing Systems," SAE Technical Paper 2015-01-1039, 2015, doi:10.4271/2015-01-1039.

Copyright (C) 2015 SAE International

\begin{abstract}
Selective catalytic reduction (SCR) has become the mainstream approach for removing heavy-duty (HD) diesel engine NOx emissions. Highly efficient SCR systems are a key enabling technology allowing engines to be calibrated for very high NOx output with a resultant gain in fuel consumption while still maintaining NOx emissions compliance. One key to the successful implementation of high efficiency SCR at elevated engine out NOx levels is the ability to introduce significantly more AdBlue into the exhaust flow while still ensuring complete ammonia production and avoiding the formation of deposits.
\end{abstract}

This paper presents a body of experimental work conducted on an exhaust test bench using optical techniques including high-speed imaging and phase Doppler interferometry (PDI), applied under representative exhaust conditions to a HD diesel engine aftertreatment system with optical access inside the mixer tube.

Two different sprays were used to dose AdBlue onto the mixing device. A three-hole injector and a single-hole pressure-swirl injector were characterised in ambient and heated exhaust flow conditions. A metallic two-stage mixer and an uncoated cordierite ceramic substrate mixer were compared and demonstrated the ability of the substrate mixer to reduce deposit formation at higher dosing rates inside the mixer tube when used with the correct spray type. High-speed imaging revealed the ability of the substrate to absorb injected AdBlue spray at cooler exhaust temperatures. However, using the incorrect spray can lead to liquid saturation inside the substrate channels, which is detrimental due to the formation of deposits on the rear face of the substrate.

\section{Introduction}

Selective catalytic reduction has become the established exhaust after-treatment technology for combating the NOx emissions of modern heavy-duty diesel engines. Today's SCR systems are capable of achieving a cycle averaged NOx reduction efficiency up to $96 \%$ [1] which enables full compliance with the most stringent current emissions legislation. These systems use a urea water solution, commercially known as AdBlue, to provide the ammonia required for the SCR reaction into the exhaust stream. Many of these systems have been optimised to operate in conjunction with engines using an EGR strategy of around $15-25 \%$ to maintain typical engine out NOx values up to $3 \mathrm{~g} / \mathrm{kWh}[\underline{2}$ ]. The continued push from regulators for $\mathrm{HD}$ diesel engines to reduce fuel consumption and $\mathrm{CO}_{2}$ emissions and realising engines with brake thermal efficiencies nearing $50 \%$ will require engine calibrations and a combustion strategy which generate high engine out NOx at levels of 8 to $12 \mathrm{~g} / \mathrm{kWh}[\underline{3}]$. These engines will require SCR systems capable of over $98 \%$ NOx reduction efficiency and due to the increased $\mathrm{NOx}$ levels will require significantly increased AdBlue injection rates into the exhaust flow in order to provide enough ammonia for the SCR reactions, but ultimately could deliver a fuel consumption improvement of nearly 3 $\%$ compared to a 2010 baseline engine [1].

While there are several aspects key to a highly efficient SCR system, including catalyst formulations and control strategies, the ability to generate and distribute the required ammonia from AdBlue is critical and often presents a number of problems. AdBlue, a fluid consisting of $32.5 \%$ urea in purified water, is sprayed into the exhaust flow upstream of the SCR catalyst. The transfer of thermal energy from the exhaust stream into the spray evaporates the majority of the water content before thermally decomposing the remaining urea by thermolysis and hydrolysis resulting in the release of gaseous ammonia. In many cases, mixing devices located downstream of the injection point are used to provide a hot surface area for spray impingement and heat transfer into the spray, and to uniformly distribute the spray and generated gases within the exhaust flow. The formation of deposits inside the SCR mixer tube, generated from undesirable reaction pathways during the thermal decomposition of the urea are a known and continual problem in SCR dosing systems. Deposit formation is a complex function of exhaust geometry, spray and exhaust flow structures, exhaust gas and wall temperatures and chemistry. Despite a significant body of work published around these subject areas $[\underline{4}, \underline{5}, \underline{6}, \underline{7}, \underline{8}, \underline{9}, \underline{10}, \underline{11}, \underline{12}]$, a complete understanding of controlling and avoiding deposit formation is still not available. 
One practice implemented to mitigate against deposit formation is to create a deposit-limited dosing map for a specific SCR system [4]]. This map defines the maximum amount of AdBlue that can be sprayed into the exhaust at a given exhaust flow rate and temperature without forming deposits over a set period of time. Ultimately, these maps can put a limitation on the NOx conversion efficiency of an SCR system. If the engine NOx level requires more ammonia than the deposit map allows, which becomes very significant at high engine out NOx levels, then insufficient ammonia will be available to conduct the SCR reactions. Therefore, being able to make step performance increases to the dosing map is critical in realising the next generation of ultra-high efficiency SCR systems.

\section{Scope of the Study}

The objective of this study was to experimentally assess the ability of a high-surface area mixing device to prevent the formation of urea derived deposits at high AdBlue dosing rates. This was achieved by modifying an after-treatment system to provide full optical access to the mixer and mixer tube. This paper describes the spray characteristics of two different AdBlue injection systems. Thee sprays were then used to dose AdBlue onto a ceramic substrate mixing device while a combination of time-lapse photography and highspeed shadow imaging have been used to observe and quantify the spray-mixer interactions for each system under representative exhaust flow conditions. The amount of any deposits formed has been evaluated and compared against a benchmark of a two-stage mixer commonly found in current SCR dosing systems.

\section{Experimental Setup}

\section{Exhaust Flow Test Facility}

In order to gather the experimental data, two identical bespoke exhaust test beds were designed and built within the Mechanical Engineering department at Loughborough University. These test beds were able to operate independently of each other and generate air flows representative of exhaust flows from a HD diesel engine. A schematic of one of the test beds is shown in Figure 1.

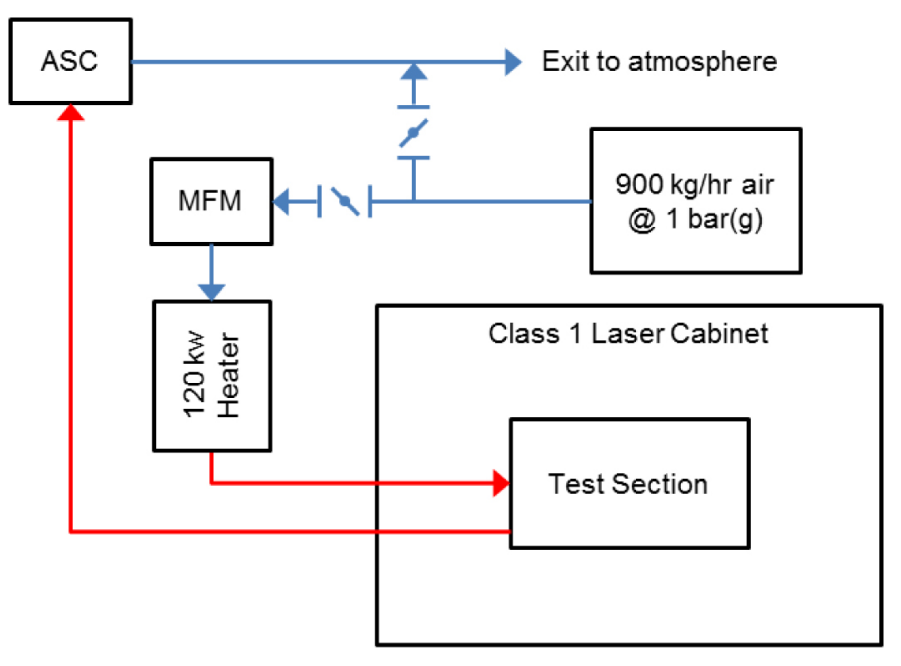

Figure 1. Schematic diagram of exhaust test bench
Each test bed comprised of a $30 \mathrm{~kW}$ air blower which supplied up to $900 \mathrm{~kg} / \mathrm{hr}$ of ambient air at a maximum pressure of $1 \mathrm{bar}(\mathrm{g})$. Air mass flow rate was modulated by splitting the flow between the main supply and a bypass line controlled by butterfly valves and measured by an in-line thermal mass flow meter (MFM). Each air supply was fed through a $120 \mathrm{~kW}$ in-line electric heater capable of heating the air to a maximum temperature of $600{ }^{\circ} \mathrm{C}$.

Due to the risks associated with the operation of Class 4 lasers for the experimental work, the test sections were contained inside a Class 1 interlocked laser-safe cabinet. The heated air supply was fed in and out of the cabinet. An ammonia slip catalyst (ASC) was installed downstream of the test sections to remove any ammonia generated before discharging to atmosphere. Atmospheric air was used throughout the entirety of the testing rather than combustion products.

\section{Optical Test Section}

All experimental work described in this paper was conducted on a HD diesel engine after-treatment module in which the standard mixer tube was replaced with an optical $97 \times 97 \mathrm{~mm}$ square profile mixer tube. The optical mixer tube was mounted immediately downstream of a sharp $90^{\circ}$ elbow and a two-stage mixing device, similar to those in $[\underline{8}, \underline{10}, 14-16]$, was located at the inlet of the mixer tube. For some of the testing, the two-stage mixer was replaced by a 400 cells per square inch (cpsi) ceramic substrate structure, acting as a highsurface area mixing device for the AdBlue spray to impact on. The AdBlue injector was located on the outside the $90^{\circ}$ elbow mounted such that the spray was discharged into the exhaust flow parallel to the centreline of the mixer tube. The distance between the injector nozzle and the leading edges of the mixing device was approximately $100 \mathrm{~mm}$. A simplified representation of the injector and mixer flow path is presented in Figure 2. A DPF located upstream of the test section ensured a consistent flow profile into the mixing device.

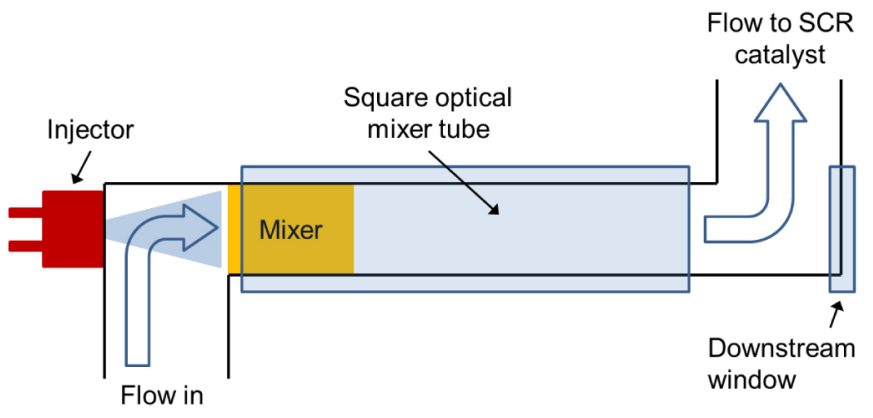

Figure 2. Schematic diagram of SCR injector and mixer location

The optical mixer tube provided visual access to the trailing edge of the mixing device and the downstream region. The two flat windows of the mixer tube were made of $5 \mathrm{~mm}$ thick quartz glass. A $3 \mathrm{~mm}$ thick flat quartz window was installed downstream of the mixer tube on a $90^{\circ}$ bend. This window allowed light to be introduced axially down the length of the mixer tube or for upstream images inside the mixer tube to be acquired. All joining surfaces were sealed with high temperature gaskets to prevent leakages. In this configuration, the optical mixer tube was able to safely operate at exhaust gas temperatures in excess of $500{ }^{\circ} \mathrm{C}$. Figure 3 shows the optical mixer tube and downstream window. 


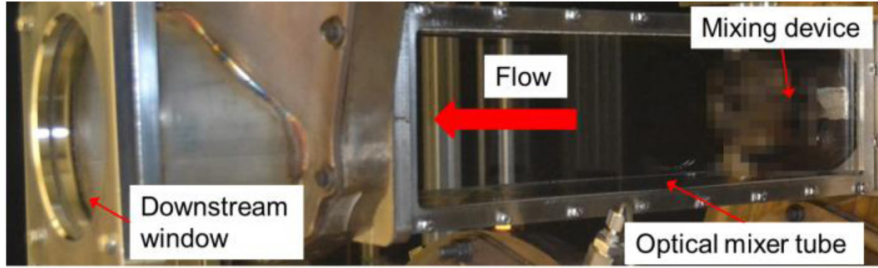

Figure 3. Optical square mixer tube and downstream window

\section{AdBlue Sprays}

This study focuses on the use of two different AdBlue dosing systems, each with their own spray characteristics, and how they interact with mixers to influence deposit formation. Both injection systems were airless, single-fluid systems using pulse width modulation at a fixed frequency of $1 \mathrm{~Hz}$ to control and vary the rate of AdBlue injection. Both systems consisted of a pumping unit connected via a pressurised line to a separate injection unit which contained a solenoid valve for injection activation. One system featured a three-hole injector and operated at a system pressure of 9 bar(a). The three orifices of the injector were arranged into an equilateral triangle and relied on the turbulent break-up of the AdBlue streams to promote spray atomisation. The second system employed a single orifice pressure-swirl injector, running at an injection pressure of 10 bar(a) to produce its spray. Both systems could achieve a range of AdBlue dosing rates from 50 to $5000 \mathrm{~g} / \mathrm{hr}$.

\section{Spray Structures}

High-speed shadowgraphy images of the two sprays in ambient conditions (Figure 4 and Figure 5) highlight the differences between their structures. The three-hole injector produced three distinct jets of fluid with long breakup lengths. In comparison the pressure-swirl injector generated a spray that atomised in a very short breakup distance resulting in a solid cone spray structure with a much more uniform distribution of spray across its cross-section. The atomisation of spray from both the injectors was seen to be consistent across the duration of each dosing event and unaffected by dosing rate.

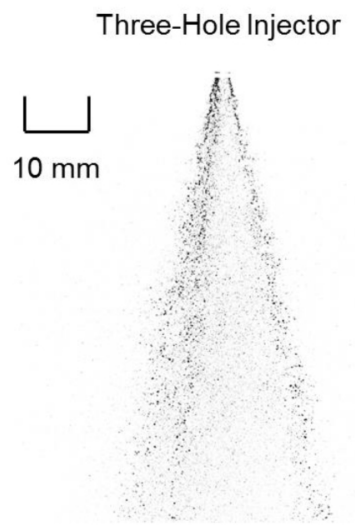

Pressure-Swirl Injector

Figure 4. Comparison of sprays in ambient conditions. AdBlue dosing rate $=$ $1000 \mathrm{~g} / \mathrm{hr}$
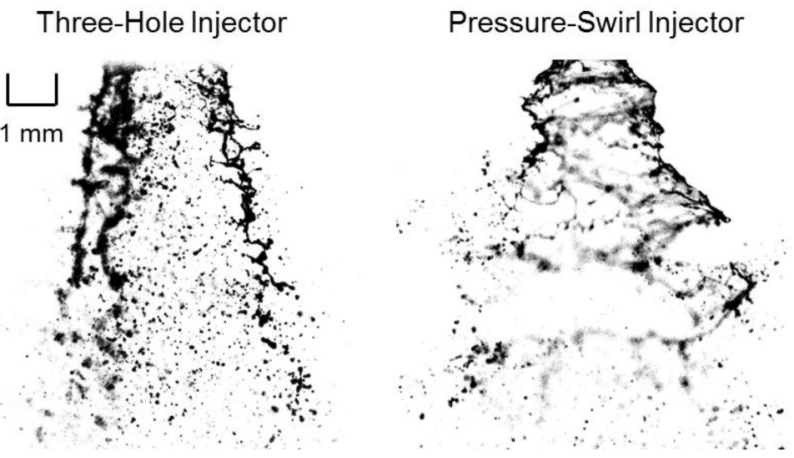

Figure 5. High-speed shadowgraphy images of spray breakup near nozzle in ambient conditions

The cone angle, the angle made by the intersection of the two outside edges of the spray at the nozzle, was determined to be $28^{\circ}$ for the three-hole injector while the pressure-swirl injector generated a spray with a wider cone angle of $40^{\circ}$. Figure 6 presents cross sections showing the distributions of the two sprays captured with laser sheet imaging at a plane $100 \mathrm{~mm}$ downstream from the point of injection. The injectors were mounted on the outside of a $90^{\circ}$ bend and injected into an airflow of $200 \mathrm{~kg} / \mathrm{hr}$ at a temperature of $350{ }^{\circ} \mathrm{C}$. Both spray structures were insensitive to deflection from the cross flow over a range of exhaust flows. It can be seen that the pressure-swirl injector generated a very distributed spray profile across the entire cross section in comparison to the concentrated spots of spray from the three-hole injector.

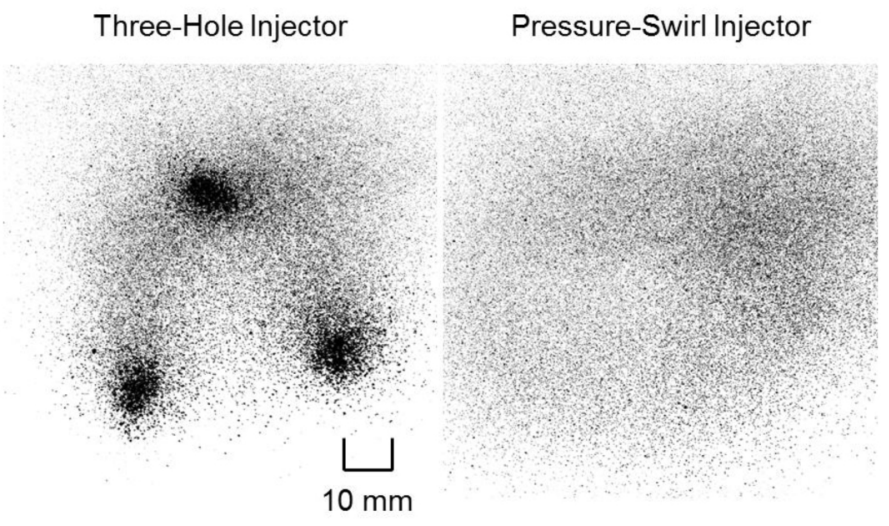

Figure 6. Comparison of spray cross-sections $100 \mathrm{~mm}$ from point of injection in an exhaust flow of $200 \mathrm{~kg} / \mathrm{hr}$ and temperature of $350^{\circ} \mathrm{C}$

\section{Spray Droplet Measurement}

Droplet diameters and velocities were measured throughout both sprays in ambient conditions using an Artium Technologies PDI-200 Phase Doppler Interferometer system. Figure 7 displays the distribution of droplet diameters across a plane $100 \mathrm{~mm}$ from the point of injection at an AdBlue dosing rate of $1000 \mathrm{~g} / \mathrm{hr}$ for both injectors. Droplets up to $395 \mu \mathrm{m}$ in diameter were measured in the spray of the three-hole injector although the majority of the droplets measured below 150 microns with a Sauter mean diameter (SMD) of $95.5 \mu \mathrm{m}$. The spray from the pressure-swirl injector was much finer with an SMD of $33.5 \mu \mathrm{m}$ and no droplets greater than $100 \mu \mathrm{m}$ measured, with most of the droplets less than 50 microns in diameter. 

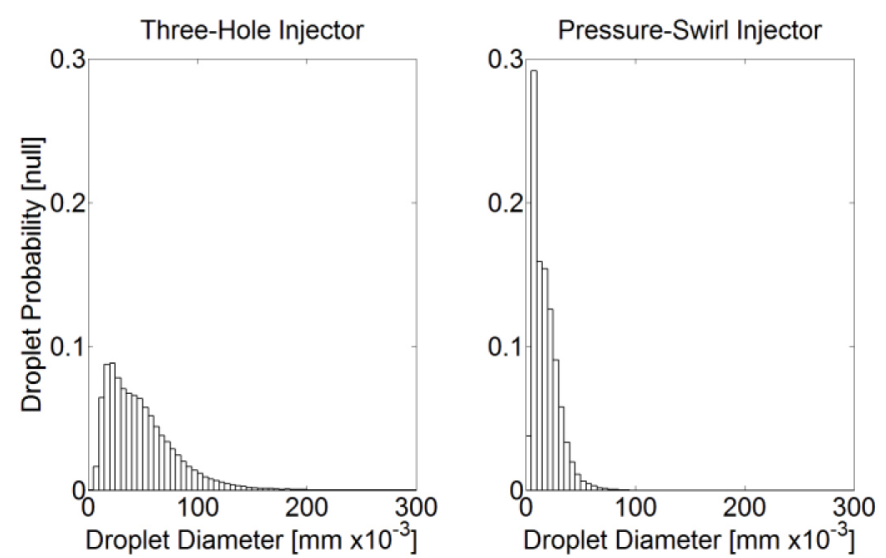

Figure 7. Histogram of droplet diameters measured across a plane $100 \mathrm{~mm}$ from point of injection. Dosing rate $=1000 \mathrm{~g} / \mathrm{hr}$

Droplet velocities measured at the same $100 \mathrm{~mm}$ plane are shown in Figure 8. In both sprays, modal droplet velocities ranged between 6 to $12 \mathrm{~m} / \mathrm{s}$. Droplet velocities up to $30 \mathrm{~m} / \mathrm{s}$ were recorded for both sprays, although the pressure-swirl spray had very few droplets with velocities over $15 \mathrm{~m} / \mathrm{s}$. Figure 9 and Figure 10 present the spread of droplet velocities and momentum respectively as a function of diameter for the two sprays.
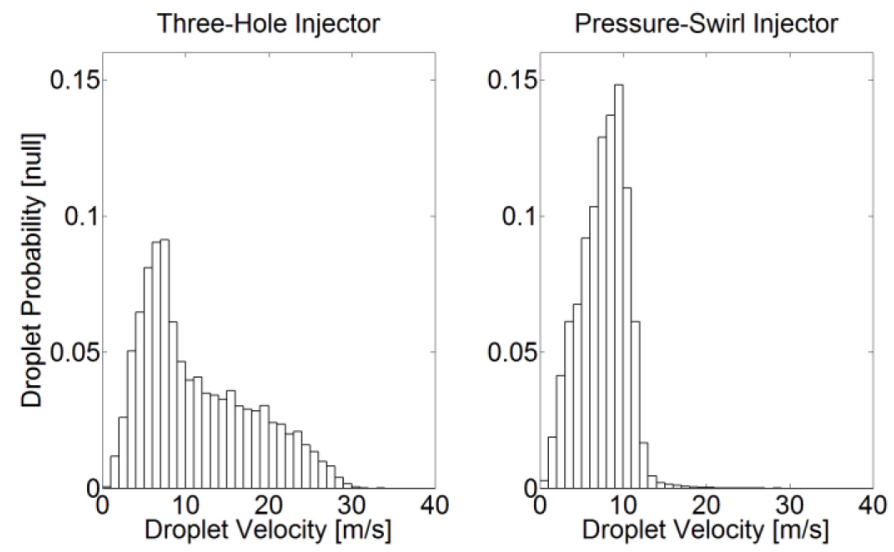

Figure 8. Histogram of droplet velocities measured across a plane $100 \mathrm{~mm}$ from point of injection. Dosing rate $=1000 \mathrm{~g} / \mathrm{hr}$
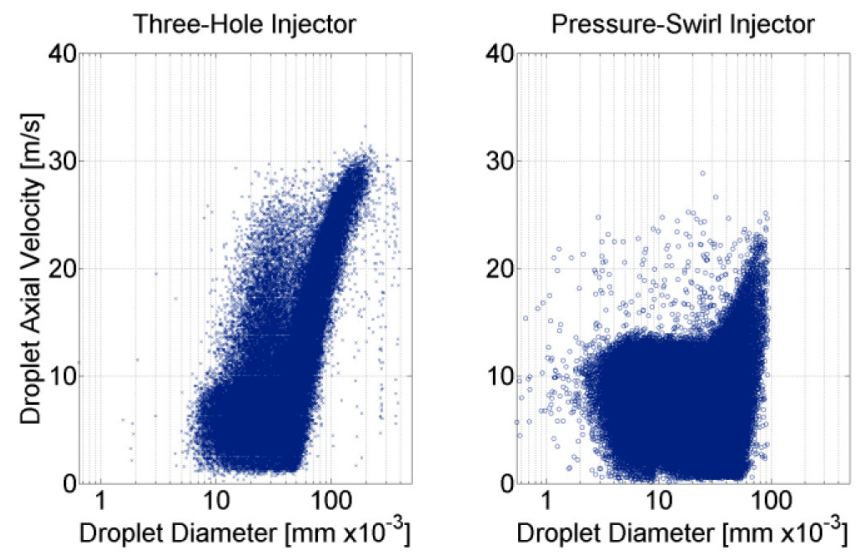

Figure 9. Droplet diameter vs velocity measured $100 \mathrm{~mm}$ from point of injection. Dosing rate $=1000 \mathrm{~g} / \mathrm{hr}$
For droplets measuring between 10 and $100 \mu \mathrm{m}$, droplet momentum was comparable between the two sprays, although the three-hole injector produced droplets above 100 microns with increased momentum whereas the pressure-swirl spray contained a greater quantity of sub 10 micron droplets with very low momentum.
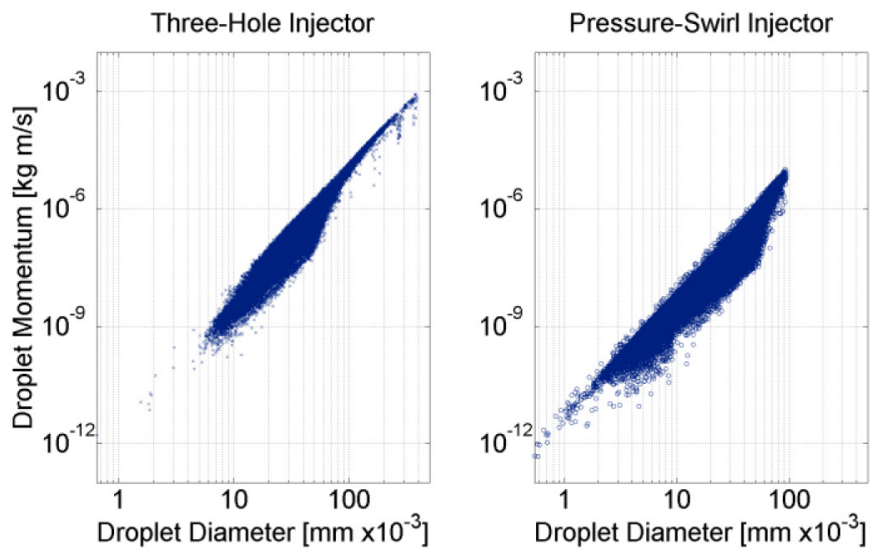

Figure 10. Droplet diameter vs momentum measured $100 \mathrm{~mm}$ from point of injection. Dosing rate $=1000 \mathrm{~g} / \mathrm{hr}$

\section{Imaging Techniques and Testing Methodology}

Throughout the testing, six steady-state exhaust flow conditions were used; three temperatures and two mass flow rates, as listed in Table 1. These conditions represented typical exhaust flows of a HD diesel engine.

Table 1. Exhaust operating conditions used during testing

\begin{tabular}{|c|c|c|}
\hline $\begin{array}{c}\text { Exhaust Condition } \\
\text { EC1 }\end{array}$ & $\begin{array}{c}\text { Exhaust Gas Temperature } \\
{\left[{ }^{\circ} \mathrm{C}\right]}\end{array}$ & $\begin{array}{c}\text { Exhaust Gas Mass Flow } \\
{[\mathrm{kg} / \mathrm{hr}]}\end{array}$ \\
\hline EC2 & 250 & 250 \\
\hline EC3 & 250 & 750 \\
\hline EC4 & 350 & 750 \\
\hline EC5 & 350 & 250 \\
\hline EC6 & 450 & 750 \\
\hline
\end{tabular}

At each exhaust condition testing was conducted across a range of AdBlue dosing rates ranging from 500 to $2000 \mathrm{~g} / \mathrm{hr}$, substantially higher than those operated at to achieve Tier 4 final levels of NOx reduction on current engines. However, at future engine out $\mathrm{NOx}$ levels of $8-12 \mathrm{~g} / \mathrm{kWh}$, these higher dosing rates will be required to generate enough ammonia for the SCR reactions.

Two imaging techniques were used throughout this study in order to gather experimental data on the interaction between the sprays and mixing devices.

\section{Deposit Time-Lapse Imaging}

Time-lapse photography was used to image the rear face of the mixer and downstream inside the mixer tube over a period of constant AdBlue dosing, allowing the formation and progression of any deposits to be captured. A Nikon D800E DSLR camera fitted with a 
$60 \mathrm{~mm}$ macro lens was positioned to image upstream through the downstream optical window (Figure 11). The camera was set with an ISO of 800 , a shutter speed of $1 / 20 \mathrm{~s}$ and at an aperture of $f 16$. The camera was triggered remotely to capture an image every 4 seconds over a 10 minute dosing period resulting in a total of 151 images per test condition. Illumination of the imaging region through the optical mixer tube windows was provided by a 900 lumen LED light.

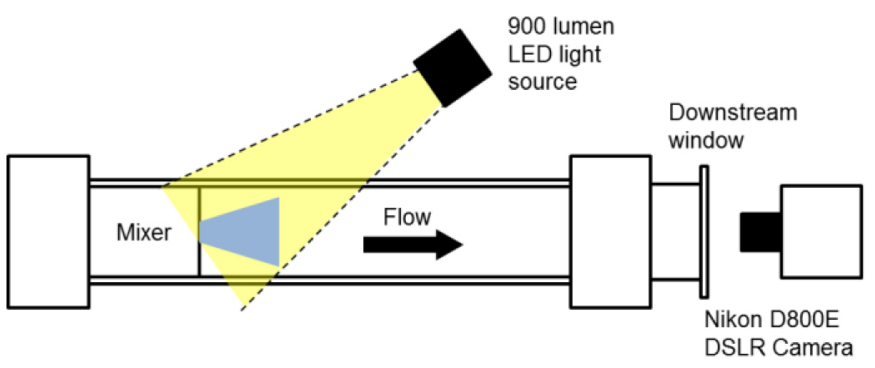

Figure 11. Mixer tube deposit time-lapse imaging setup schematic

At each steady-state exhaust condition, dosing was maintained at a constant rate over the 10 minute period, with the mixer and mixer tube initially free from deposits. After a test, any deposits present were either removed by increasing the exhaust temperature to $450{ }^{\circ} \mathrm{C}$ until the deposits fully decomposed or by cooling the rig and manually remove the deposits.

In order to allow a quantitative comparison of the amount of deposits formed at different exhaust conditions, dosing rates and hardware configurations, a subjective ranking was used to assign a value to the final image of each time-lapse series. The severity of any deposits observed on the mixer and throughout the mixer tube was scored between zero and five. A ranking of zero represented no deposits anywhere within the mixer tube while a ranking of five correlated to a significant presence of deposits distributed throughout the mixer tube, with increasing integer values in-between correlating to an increasing presence of deposits.

\section{High-Speed Imaging of Spray at the Mixer Outlet}

High-speed shadowgraphy imaging was conducted at the outlet of the mixer to understand how the spray interacted with the mixer over the duration of an injection event. A LaVision Imager Pro HS4M 12-bit digital high-speed CMOS camera fitted with a $105 \mathrm{~mm}$ lens was positioned to image through the optical mixer tube focussed at the trailing edge of the mixer. The camera was operated at a frame rate of $2000 \mathrm{~Hz}$ at a resolution of $1440 \times 1700$ pixels. A LaVision highspeed laser diffuser placed on the opposite side of the mixer tube provided a uniform background illumination to generate the shadowgraphy images. The beam from a Litron LDY304 Nd:YLF high-speed pulsed laser, with a maximum energy output of $30 \mathrm{~mJ}$ per pulse at a rate of $2 \mathrm{kHz}$ and pulse duration of $150 \mathrm{~ns}$ was mirrored into the diffuser. The camera and laser were synchronised through a LaVision high speed controller. A schematic of the high-speed shadowgraphy arrangement is shown in Figure 12. At each test condition, the mixer and mixer tube were initially free from any deposits prior to AdBlue injection. High-speed imaging was typically captured within the first 10 seconds of dosing.

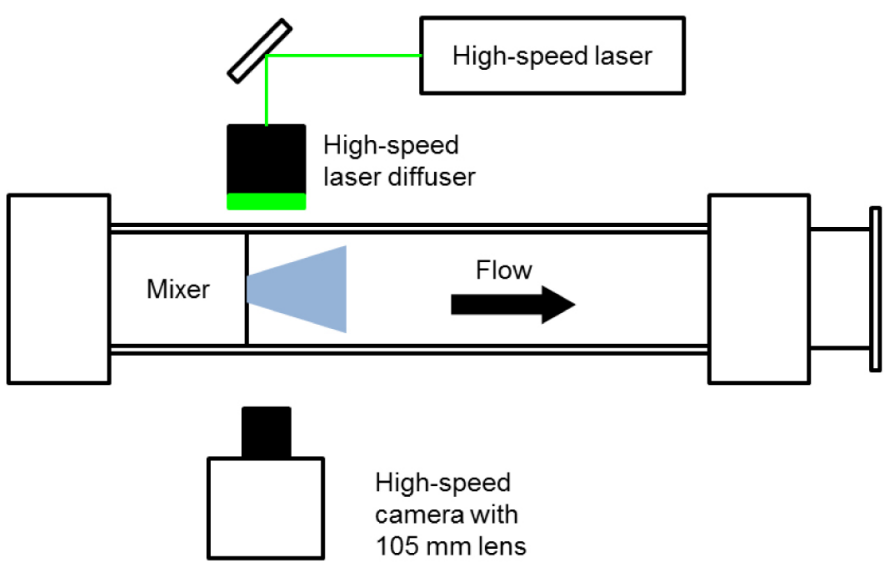

Figure 12. Mixer high-speed imaging experimental setup schematic

\section{Results and Discussion}

\section{Two-Stage Mixer Baseline}

The original mixing device was based around a metallic two-stage plate mixer, optimised to work with the high-momentum spray generated by the three-hole injector. The plates of the mixer provided a hot surface on which the larger droplets produced by the three-hole injector could impact upon and breakup into smaller droplets with increased evaporation and decomposition rates.

A significant amount of experimental testing was initially conducted using the two-stage mixer with both sprays. A combination of high-speed imaging at the trailing edge of the mixer and deposit time-lapse imaging at the back face revealed the formation of liquid films on the surfaces of the mixer as a result of spray impaction when dosing AdBlue at rates up to six times higher than those seen during normal operation. Previous studies have also experienced the formation of liquid films on the surfaces of two-stage plate mixers [7]. The formation of liquid films had two consequences. The first was a direct formation of deposits on the mixer vane surfaces where the liquid films accumulated and occurred at all temperatures tested. The second was the stripping of the liquid films due to aerodynamic interactions during which large droplets were ejected from the liquid film and impacted further downstream on surfaces of the mixer tube where they formed further deposits at exhaust temperatures below $450{ }^{\circ} \mathrm{C}$. At low exhaust flow rates, once the liquid film had become fully developed one or two droplets ranging from 1-5 mm in diameter would be ejected per injection event. At high exhaust flow rates a smaller liquid film would eject many more droplets between 0.5 and $2 \mathrm{~mm}$ in diameter at a high frequency. This mechanism of deposit formation occurred with both injection systems, although the initial onset of the initial liquid filmed occurred at a higher dosing rate with the pressure-swirl spray.

Table 2 presents the deposit severity rankings at all six exhaust conditions for a range of dosing rates when the pressure-swirl injector was used with the original two-stage mixer. The values in brackets indicate the score given at the same exhaust condition and dosing rate but with the three-hole injector. With both injectors, the amount of deposits increased with an increase in dosing rate, and a reduction in both exhaust gas temperature and mass flow rate. 
Table 2. Ranking of deposit severity based on time-lapse images with two-stage mixer and pressure-swirl injector

\begin{tabular}{|c|c|c|c|c|}
\hline $\begin{array}{c}\text { Deposit } \\
\text { Severity } \\
\text { Ranking }\end{array}$ & \multicolumn{5}{|c|}{ AdBlue Dosing Rate $[\mathrm{g} / \mathrm{hr}]$} \\
\hline $\begin{array}{c}\text { Exhaust } \\
\text { Condition }\end{array}$ & $\mathbf{5 0 0}$ & $\mathbf{1 0 0 0}$ & $\mathbf{1 5 0 0}$ & $\mathbf{2 0 0 0}$ \\
\hline EC1 & $2(3)$ & $5(5)$ & No Data (5) & No Data (-) \\
\hline EC2 & $0(2)$ & $3(3)$ & No Data (4) & No Data (-) \\
\hline EC3 & $1(2)$ & $1(4)$ & $4(5)$ & No Data (-) \\
\hline EC4 & $0(0)$ & $0(1)$ & 1 (2) & 2 (3) \\
\hline EC5 & $0(0)$ & $0(2)$ & No Data (3) & 1 (4) \\
\hline EC6 & $0(0)$ & $0(0)$ & No Data (1) & 0 (1) \\
\hline
\end{tabular}

It can be seen from Table 2 that the pressure-swirl injector offered a benefit in reducing the amount of deposits when compared to the three-hole injector at many of the conditions tested, with significant reductions at EC3 with a dosing rate of $1000 \mathrm{~g} / \mathrm{hr}$ and at EC5 at a dosing rate of $2000 \mathrm{~g} / \mathrm{hr}$. At these conditions significant amounts of deposits remained after 10 minutes of dosing with the three-hole injector but switching to the pressure swirl reduced these deposits to negligible amounts. At other exhaust conditions such as EC1 and EC2, the pressure-swirl injector reduced deposits at a dosing rate of $500 \mathrm{~g} / \mathrm{hr}$ but once the dosing rate was doubled to $1000 \mathrm{~g} / \mathrm{hr}$, the severity of the deposits with both injectors were comparable.

The improvement seen with the pressure-swirl injector was attributed to the wider spray angle, smaller SMD and more uniform distribution of spray which resulted in better utilisation of the available surface area of the two-stage mixer compared to the three-hole injector. The targeted jets of the three-hole injector and larger droplet size had the effect of locally cooling the impaction sites on the mixer. The pressure-swirl spray reduced localised heat flux from spray impaction on the surfaces of the mixer and the subsequent formation of liquid films that was the starting point for deposit formation was also reduced. However, at higher dosing rates the fact that the deposit severity became insensitive to the spray type suggests that the capacity of the mixer began limiting the capability of the system to extract thermal energy from the exhaust stream and transfer it into the spray mass to enable successful urea decomposition.

A mixer with a much greater surface area should therefore be able to further reduce deposit formation at a given exhaust condition by being able to collect more heat from the exhaust flow through increased convection, and simultaneously impart more of that energy into the AdBlue spray during impaction.

\section{High-Surface Area Substrate Mixer}

A 400 cpsi uncoated cordierite ceramic substrate, typically used in automotive catalysts, was employed as a high-surface area mixing device. Each extruded square profile channel measured $1.15 \mathrm{~mm} \times$ $1.15 \mathrm{~mm}$. Figure 13 shows the front face of the substrate mixer along with an image of the channels when viewed through a microscope.

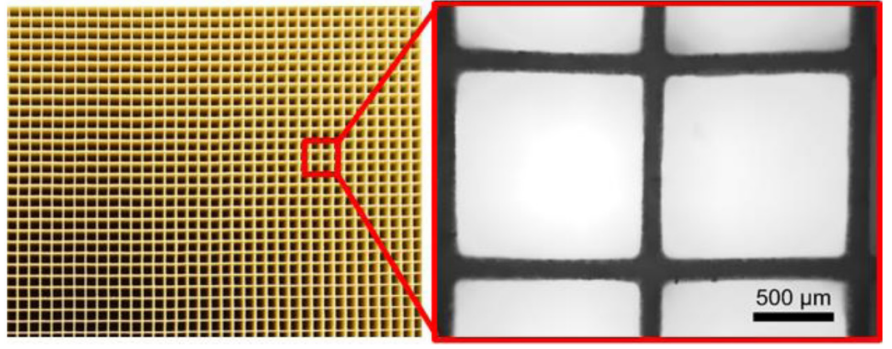

Figure 13. 400 cpsi uncoated ceramic substrate used for a high-surface area mixing device

An $80 \mathrm{~mm}$ long section of substrate was cut to shape and fitted inside the optical mixer tube replacing the original metallic two-stage mixer. The total surface area of the substrate mixer channels was approximately $2500 \%$ greater than that of the two-stage mixer.

\section{Substrate Mixer with Three-Hole Injector}

The substrate mixer was initially used in conjunction with the three-hole injector to assess whether or not the increased surface area in comparison to the two-stage mixer would lead to a reduction in deposit formation. Deposit formation over a 10 minute period was captured with time-lapse photography and the severity ranked for all six exhaust conditions at a range of AdBlue dosing rates from 250 to $2000 \mathrm{~g} / \mathrm{hr}$.

\section{Exhaust Mass Flow Rate}
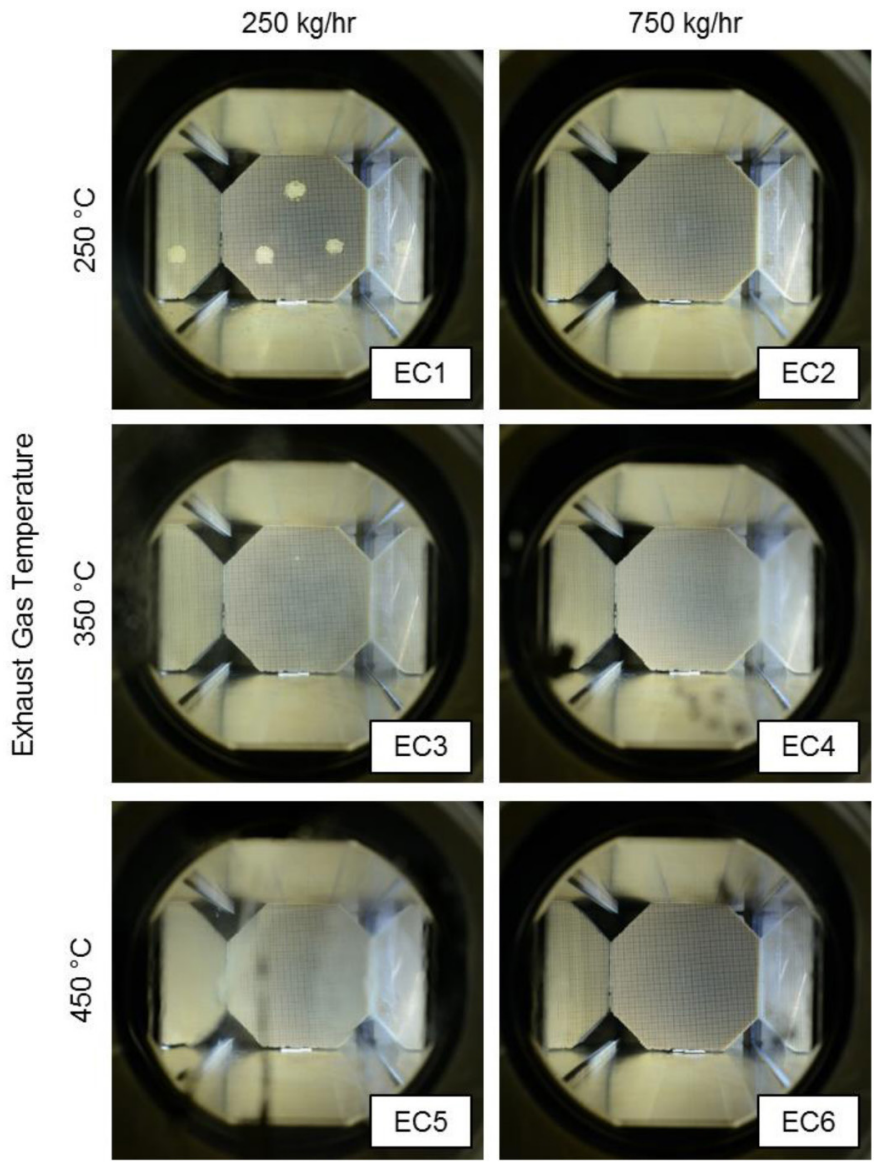

Figure 14. Time-lapse images of the substrate mixer and mixer tube after 10 minutes of dosing AdBlue at rate of $500 \mathrm{~g} / \mathrm{hr}$ with three-hole injector 
Time-lapse images captured observing the downstream face of the substrate mixer taken after dosing AdBlue at a rate of $500 \mathrm{~g} / \mathrm{hr}$ over a 10 minute period are shown in Figure 14 for all six exhaust conditions. The back of the substrate mixer and inside the mixer tube remained free from deposits at four of the conditions. However, at EC3 and more noticeably at EC1, lighter spots were present on the downstream face of the substrate. At EC1, three spots, each approximately $10 \mathrm{~mm}$ in diameter were formed. The spots indicated the presence of liquid AdBlue and that the channel had become fully saturated with spray. At EC1, the first signs of saturation began after approximately 200 seconds of dosing and then continued to grow over the remaining dosing period. The arrangement of the three spots corresponded to the jets produced by the three-hole injector. At EC3, a very small spot could be identified towards the top of the substrate as some of the channels became saturated.

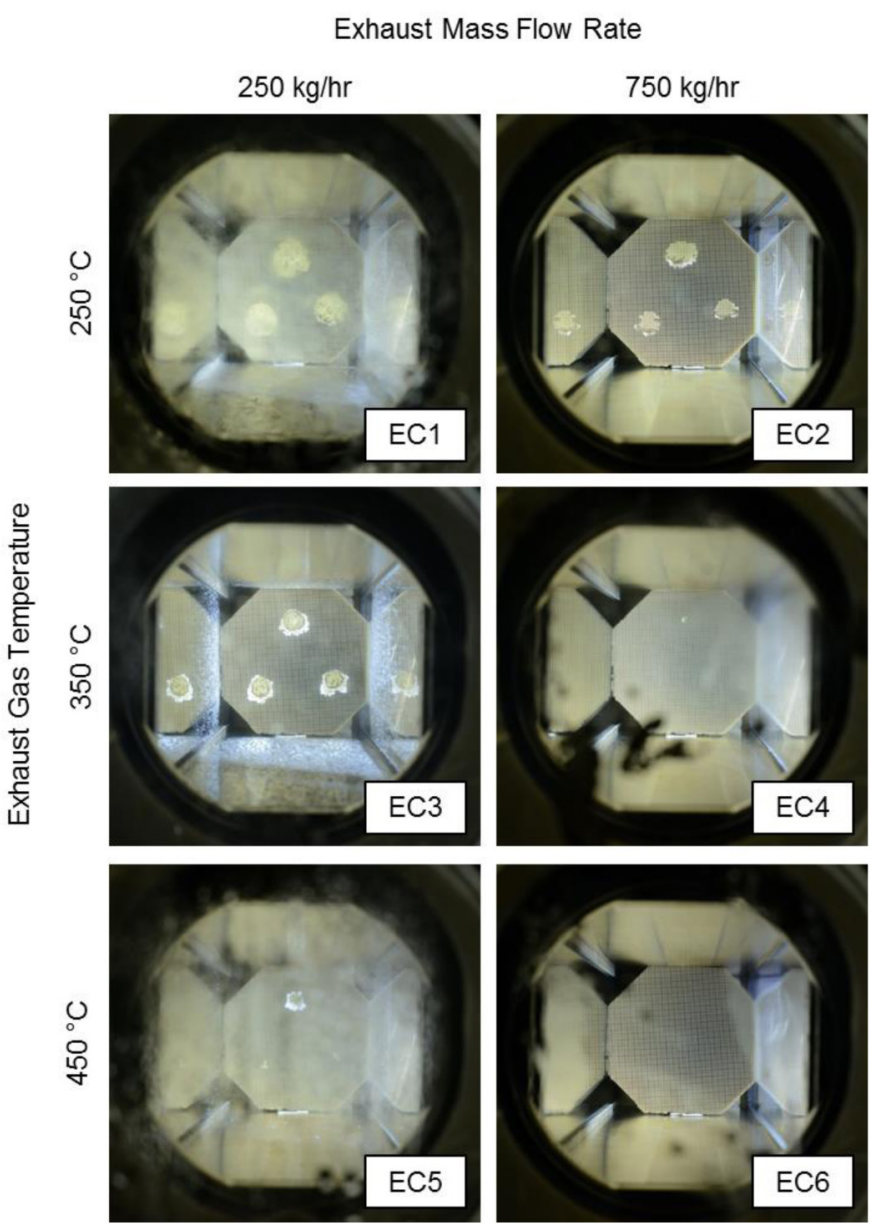

Figure 15. Time-lapse images of the substrate mixer and mixer tube after 10 minutes of dosing AdBlue at rate of $1000 \mathrm{~g} / \mathrm{hr}$ with three-hole injector

Images shown in Figure 15 were taken at a dosing rate of $1000 \mathrm{~g} / \mathrm{hr}$. Doubling the dosing rate led to some level of saturation at all conditions with the exception of EC6. At EC1, the onset of saturation began after 1 minute. After 2 minutes, spitting emanating from the saturated regions began leading to significant wall wetting on the downstream surfaces of the mixer tube. The size of the saturation regions increased to approximately $20 \mathrm{~mm}$ in diameter after 5 minute of dosing. At EC3, initial saturation could be seen after the first $80 \mathrm{~s}$ of dosing with spitting and wall wetting again occurring after 2 minutes leaving a coating of white deposits distributed over the walls of the mixer tube. After 6 minutes, white rings started to form and develop around each saturation spot on the back of the mixer. The same white rings were also formed at EC2 and at EC4, 5 and 6 at higher dosing rates.

As seen with the formation of liquid films on the two-stage mixer, saturation of the substrate channels occurred the quickest and most readily at low exhaust temperatures, low mass flow rates and at high dosing rates.

Also observed with the substrate mixer was a tendency for deposits to form on the rear imaging window downstream of the mixer tube, even when there was no evidence of channel saturation or deposit formation on the substrate mixer, as displayed in Figure 16.
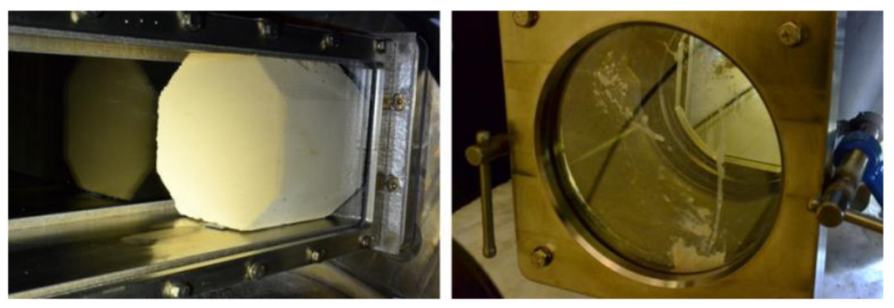

Figure 16. Urea deposits on rear window at EC6 with no mixer or mixer tube deposits after 10 minutes of dosing at $1000 \mathrm{~g} / \mathrm{hr}$

Deposits in this location were not seen to form when the two-stage mixer was fitted. However, with the substrate mixer they occurred at all conditions tested with two exceptions; at EC1 with a dosing rate of $250 \mathrm{~g} / \mathrm{hr}$ and at EC2 at a dosing rate of $500 \mathrm{~g} / \mathrm{hr}$. At both of these low temperature $\left(250^{\circ} \mathrm{C}\right)$ operating points, the substrate mixer did not become saturated (Figure 17).

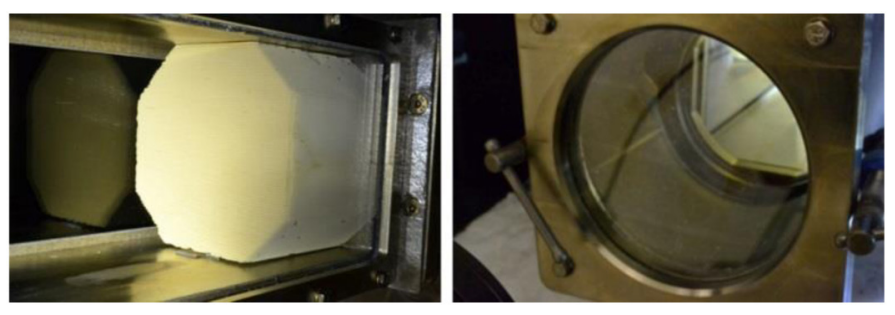

Figure 17. No substrate saturation or rear window deposits after 10 minutes of dosing at EC2, dosing rate $=500 \mathrm{~g} / \mathrm{hr}$

Two processes have been identified to explain the formation of the deposits seen on the rear window due to the substrate mixer. The extruded profile of the substrate mixer allowed a straight flow path through which the injected spray could pass unimpeded, with no mixer surface directly in the trajectory of the spray. The extruded profile also acted as a flow straightener creating a uniform flow profile downstream of the mixer with very little cross-stream mixing that allowed the droplets to continue until their momentum resulted in them impacting on the downstream window. This could be seen to occur from the time-lapse images and occurred at EC3, 4, 5 and 6 at all dosing rates and consistently over the 10 minute dosing period. This attribute of the substrate mixer was responsible for the deposits seen in Figure 16 where there was no mixer saturation or deposit formation at the mixer. It should also be noted that no spray was seen passing through the substrate mixer when the exhaust gas temperature was $250{ }^{\circ} \mathrm{C}$ at both flow rates (EC1 and EC2). 
The other process which led to the formation of deposits on the rear window only occurred once the channels of the substrate became saturated. Liquid films present on the downstream face of the substrate were stripped by the air flow discharging through nearby channels and the droplets entrained in the flow eventually impacted on the rear window. Examples of this are shown in Figure 18 and Figure 19. The ejected droplets also impacted on the walls of the mixer tube forming further deposits.
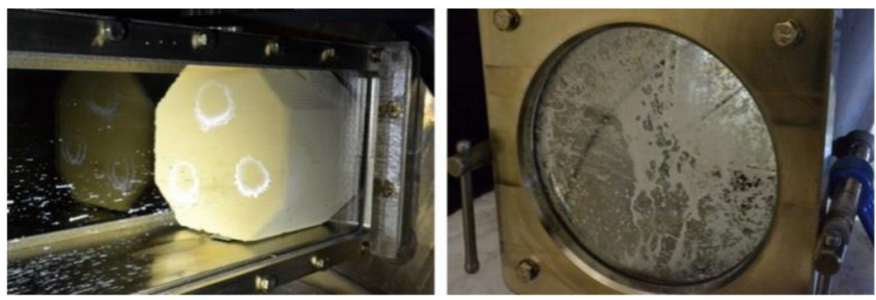

Figure 18. Urea deposits on rear window due to substrate saturation after 10 minutes of dosing at EC2, dosing rate $=1500 \mathrm{~g} / \mathrm{hr}$
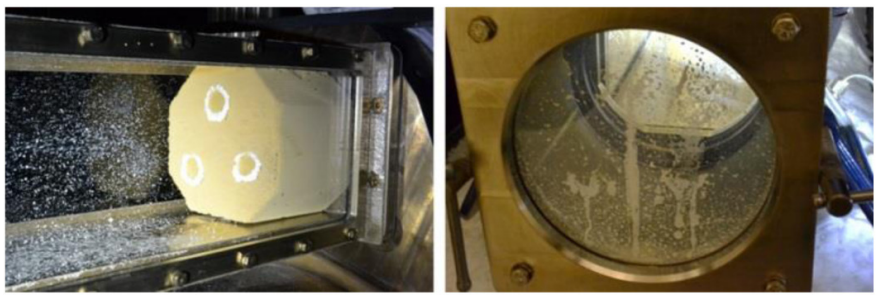

Figure 19. Urea deposits on rear window due to substrate saturation after 10 minutes of dosing at EC5, dosing rate $=2000 \mathrm{~g} / \mathrm{hr}$

The angled surfaces and vanes of the two-stage mixer presented obstructions to the trajectory of the spray resulting in droplet impingement and also created a strong mixing flow inside the mixing tube to disperse the droplets, both of which prevented the formation of deposits on the rear window. Deposit severity rankings are summarised in Table 3 for all the conditions and dosing rates tested at with the three-hole injector and substrate mixer. Corresponding values for the three-hole injector with the two-stage mixer are shown in brackets.

Table 3. Ranking of deposit severity based on time-lapse images with $400 \mathrm{cpsi}$ substrate mixer and three-hole injector

\begin{tabular}{|c|c|c|c|c|}
\hline $\begin{array}{c}\text { Deposit } \\
\text { Severity } \\
\text { Ranking }\end{array}$ & \multicolumn{5}{|c|}{ AdBlue Dosing Rate $[\mathrm{g} / \mathrm{hr}]$} \\
\hline $\begin{array}{c}\text { Exhaust } \\
\text { Condition }\end{array}$ & $\mathbf{5 0 0}$ & $\mathbf{1 0 0 0}$ & $\mathbf{1 5 0 0}$ & $\mathbf{2 0 0 0}$ \\
\hline EC1 & $2(3)$ & $5(5)$ & No Data (5) & No Data (-) \\
\hline EC2 & $1(2)$ & $2(3)$ & $4(4)$ & No Data (-) \\
\hline EC3 & $1(2)$ & $5(4)$ & $5(5)$ & No Data (-) \\
\hline EC4 & $1(0)$ & $2(1)$ & No Data (2) & 5 (3) \\
\hline EC5 & $1(0)$ & $3(2)$ & $5(3)$ & No Data (4) \\
\hline EC6 & $1(0)$ & $1(0)$ & No Data (1) & $4(1)$ \\
\hline
\end{tabular}

Compared to the two-stage mixer, the substrate mixer only marginally reduced deposits at $\mathrm{EC} 1,2$, and 3 at dosing rate of $500 \mathrm{~g} /$ $\mathrm{hr}$ (and also at $1000 \mathrm{~g} / \mathrm{hr}$ at EC2). At all other exhaust conditions and dosing rates, the same or an increased coverage of deposits occurred when using the substrate mixer. In some cases, such as at EC4, 5, and 6 at low dosing rates, this was due to the small amount of deposits formed on the rear window from direct spray impingement despite a deposit free mixer and mixer tube. In other cases saturation of the substrate and associated deposits were responsible for the higher deposit severity rankings.

\section{Spray High-Speed Imaging at Substrate Outlet}

To further examine and assess the amount of spray droplets passing through the substrate mixer high-speed shadowgraphy imaging was conducted at the outlet of the substrate mixer at all six exhaust conditions. At each condition, data was collected within the first 10 seconds of dosing, before any potential channel saturation occurred. The images were then processed using LaVision DaVis software to quantify the amount of droplets over an injection event. The steps used to process a series of spray images to extract a measure of spray droplets is listed below.

1. Background removal by subtracting first image from all subsequent images

2. Convert to binary image using fixed pixel intensity threshold. Binary image; spray $=0$, background $=1$

3. Define fixed pixel area within each image that spray passes through

4. Count all pixels inside defined area with intensity value $=0$ (spray)

5. Plot pixel count against image number (time)

Plots of all six exhaust conditions at a dosing rate of $500 \mathrm{~g} / \mathrm{hr}$ and at $1000 \mathrm{~g} / \mathrm{hr}$ are presented in Figure 20 and Figure 21 respectively. Both plots indicate at $\mathrm{EC} 1$ and $\mathrm{EC} 2\left(250{ }^{\circ} \mathrm{C}\right)$ that no droplets were detected at both dosing rates across the full spray events. At all other conditions some quantity of spray droplets were measured across the entirety of the spray event. At both dosing rates the most spray downstream of the substrate mixer occurs at EC5 followed by EC6, both at $450{ }^{\circ} \mathrm{C}$. Less spray was detected at the two $350{ }^{\circ} \mathrm{C}$ conditions.

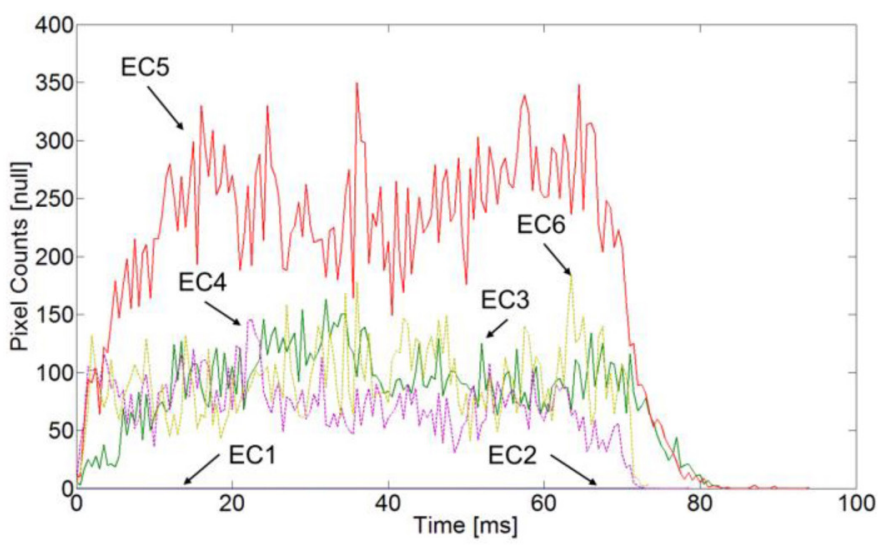

Figure 20. Quantitative analysis of high-speed imaging of spray discharging from substrate mixer with three-hole injector at a dosing rate $=500 \mathrm{~g} / \mathrm{hr}$

This analysis indicates that at $250{ }^{\circ} \mathrm{C}$, the substrate mixer was capturing all the injected droplets which promoted quick saturation of the channels. At hotter temperatures, the ability of the substrate to 
retain all the spray mass was reduced, therefore some of the droplets passed through the mixer leaving less fluid to be captured requiring more time or a higher dosing rate for any saturation to occur.

Comparing Figure 20 and Figure 21 a decrease in the spray quantity detected at EC3, EC4, EC5 and EC6 can be seen as dosing rate was increased.

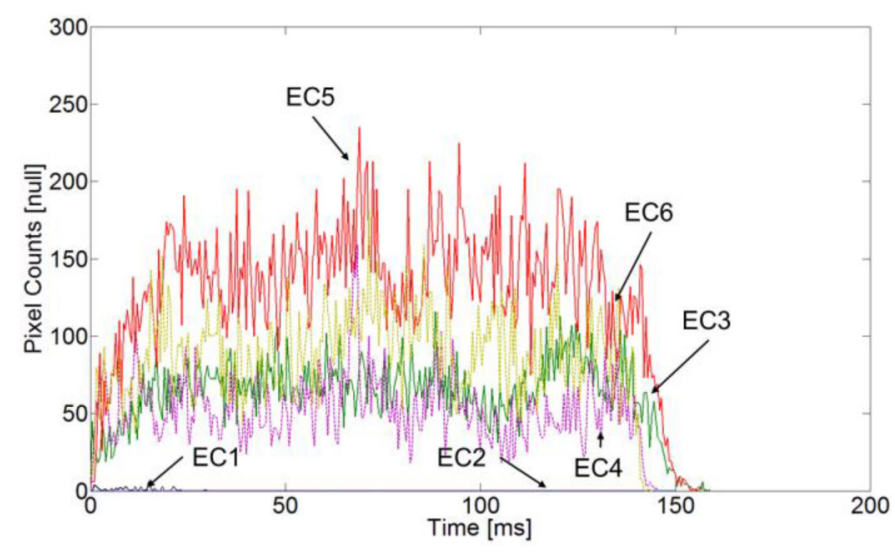

Figure 21. Quantitative analysis of high-speed imaging of spray discharging from substrate mixer with three-hole injector at a dosing rate $=1000 \mathrm{~g} / \mathrm{hr}$

This trend of decreasing amount of spray discharged from the substrate mixer with an increase in dosing rate in highlighted in Figure 22 which shows plots of spray count at EC5 at dosing rates of $500 \mathrm{~g} / \mathrm{hr}, 1000 \mathrm{~g} / \mathrm{hr}$ and $2000 \mathrm{~g} / \mathrm{hr}$.

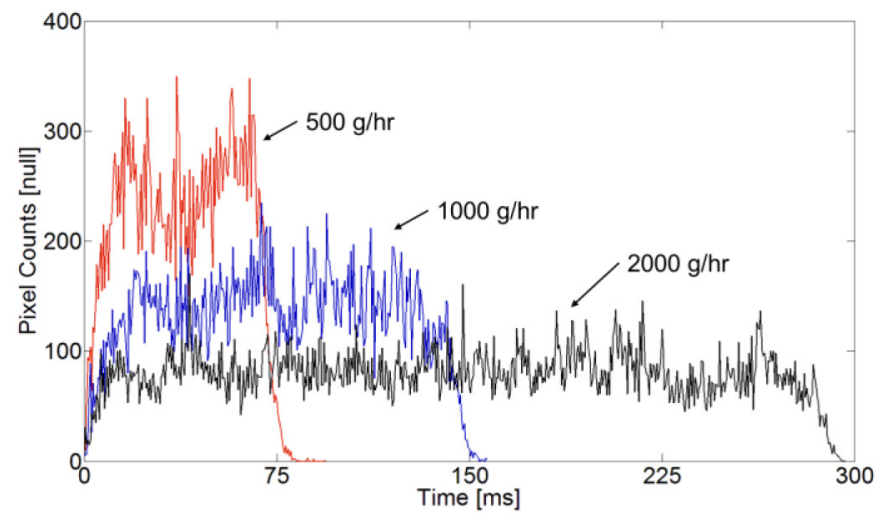

Figure 22. Quantitative analysis of high-speed imaging of spray discharging from substrate mixer with three-hole injector at EC5 at 3 dosing rates

As dosing rate was increased, the surface temperature of the substrate mixer decreased as more heat was transferred to the droplets. As seen in Figure 20 and Figure 21, lower temperatures resulted in less spray discharged and the substrate mixer absorbing a greater percentage of the initial spray.

\section{Substrate Mixer with Pressure-Swirl Injector}

The substrate mixer with the three-hole injector did not demonstrate a significant performance gain in being able to increase dosing rates while avoiding deposit formations compared to the two-stage mixer. This was in part due to liquid saturation of the channels of the substrate where the jets of the spray hit. The pressure-swirl mixer had already shown to reduce deposits on the two-stage mixer due to its more distributed and finer spray. Therefore, this spray should also be better suited to maximising the high-surface area of the substrate mixer and yield higher dosing rates without the presence of deposits. Time-lapse imaging of deposit formation and high-speed imaging of the spray were both repeated with the same substrate mixer and the pressure-swirl injector over the same range of high dosing rates.

With the pressure-swirl injector, minimal localised saturation of the substrate only occurred at one condition; at EC1 with a dosing rate of $1500 \mathrm{~g} / \mathrm{hr}$. At a dosing rate of $1000 \mathrm{~g} / \mathrm{hr}$ at EC1 there was no indication of substrate saturation or deposits in the mixer tube. In comparison with the three-hole injector, significant saturation and spitting occurred at this condition and with the two-stage mixer significant deposits formed on the mixer and inside the mixer tube with both injectors.

However, as seen with the substrate mixer and three-hole injector, spray droplets consistently impacted on the rear imaging window resulting in small deposits. This occurred continually across the 10 minute dosing period at all conditions, even at exhaust temperatures of $250{ }^{\circ} \mathrm{C}$ which did not happen with the three-hole injector.

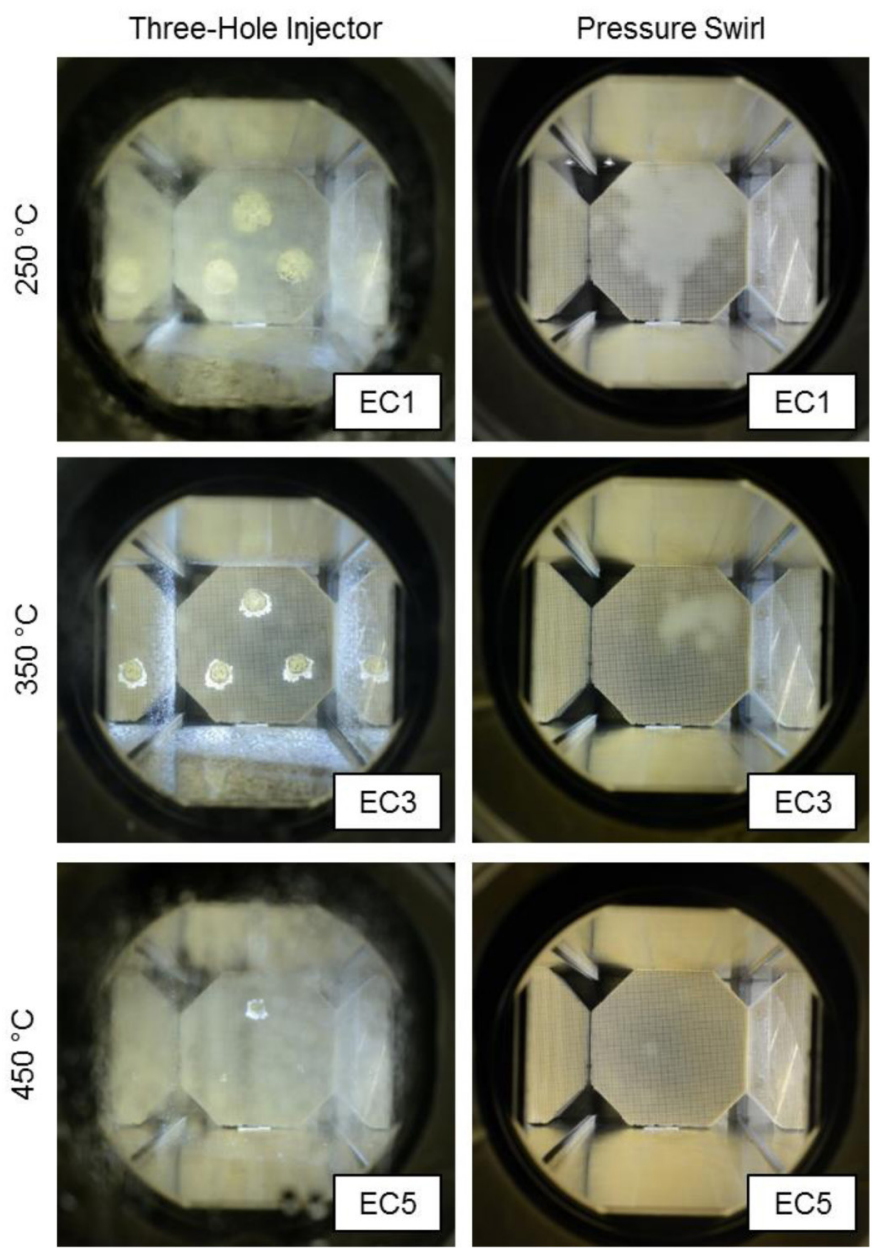

Figure 23. Three-hole injector and pressure-swirl injector with substrate mixer after 10 minutes dosing at a rate of $1000 \mathrm{~g} / \mathrm{hr}$ at EC1, EC3 and EC5

Figure 23 compares images after 10 minutes of dosing at a rate of $1000 \mathrm{~g} / \mathrm{hr}$ with both injectors onto the substrate mixer at an exhaust flow rate of $250 \mathrm{~kg} / \mathrm{hr}$. At all three exhaust temperatures the substrate mixer became saturated with the three-hole spray with deposits on the walls of the mixer tube at 250 and $350^{\circ} \mathrm{C}$ and significant wetting on the rear window at $450{ }^{\circ} \mathrm{C}$. At all three conditions some minor spray 
impaction on the rear window was evident with the pressure-swirl spray but no deposits on the substrate mixer or the walls of the mixer tube occurred.

Deposit severity rankings from the time-lapse images for the substrate mixer with the pressure-swirl injector are summarised in Table 4. Corresponding values for the pressure-swirl injector with the metallic two-stage mixer are shown in brackets.

Table 4. Ranking of deposit severity based on time-lapse images with $400 \mathrm{cpsi}$ substrate mixer and pressure-swirl injector

\begin{tabular}{|c|c|c|c|c|}
\hline $\begin{array}{l}\text { Deposit } \\
\text { Severity }\end{array}$ & \multicolumn{4}{|c|}{ AdBlue Dosing Rate [g/hr] } \\
\hline $\begin{array}{l}\text { Exhaust } \\
\text { Condition }\end{array}$ & 500 & 1000 & 1500 & 2000 \\
\hline EC1 & $1(2)$ & $1(5)$ & $2(-)$ & No Data (-) \\
\hline EC2 & $\begin{array}{ll}0 & (0)\end{array}$ & 1 (3) & $1 \quad(-)$ & No Data (-) \\
\hline EC3 & 1 (1) & 1 (1) & No Data (4) & $2(-)$ \\
\hline EC4 & $\begin{array}{ll}0 & (0)\end{array}$ & $2(0)$ & No Data (1) & $3(2)$ \\
\hline EC5 & $1 \quad(0)$ & $1(0)$ & No Data (-) & 1 (1) \\
\hline EC6 & $\begin{array}{ll}0 & (0)\end{array}$ & $1(0)$ & No Data (-) & $1(0)$ \\
\hline
\end{tabular}

At an exhaust gas temperature of $250{ }^{\circ} \mathrm{C}$ deposit severity was significantly reduced by switching to the substrate mixer at both exhaust flow rates (EC1 and EC2). A ranking value of one, indicating negligible amounts of deposits was applied in many cases due to a small amount of spray impaction on the rear window. In some cases such as EC3 and EC4 at a dosing rate of $2000 \mathrm{~g} / \mathrm{hr}$ deposits on the rear window were more prevalent resulting in a ranking of two or three.
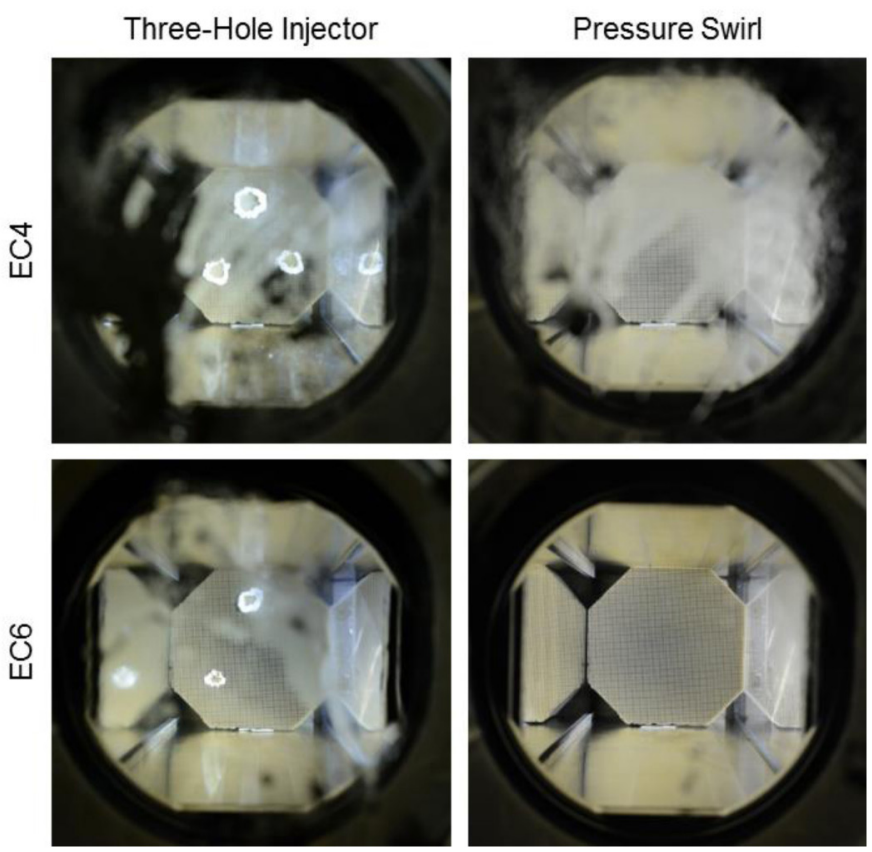

Figure 24. Three-hole injector and pressure-swirl injector with substrate mixer after 10 minutes dosing at a rate of $2000 \mathrm{~g} / \mathrm{hr}$ at EC4 and EC6
A comparison of deposits with the two injectors at a dosing rate of $2000 \mathrm{~g} / \mathrm{hr}$ at an exhaust flow of $750 \mathrm{~kg} / \mathrm{hr}$ is presented in Figure 24. Again, with the three-hole injector saturation resulted in the formation of deposit rings on the back of the substrate and spitting onto the rear window. However, with the pressure-swirl injector, the substrate remained deposit free and direct spray impingement on the rear window was responsible for a small amount of deposit formation.

Analysis of high-speed imaging to quantitatively evaluate the spray discharging from the substrate mixer was carried out with the pressure-swirl spray. Figure 25 shows the spray measured downstream of the substrate at an exhaust flow rate of $250 \mathrm{~kg} / \mathrm{hr}$ at temperatures of $250{ }^{\circ} \mathrm{C}(\mathrm{EC} 1), 350{ }^{\circ} \mathrm{C}(\mathrm{EC} 3)$ and $450{ }^{\circ} \mathrm{C}(\mathrm{EC} 5)$ at a constant dosing rate of $1500 \mathrm{~g} / \mathrm{hr}$. As seen with the three-hole injector, the amount of spray detected increased with an increase in exhaust gas temperature. Very small amounts of spray were consistently observed at $250{ }^{\circ} \mathrm{C}$ with the pressure-swirl injector, but with the three-hole injector no droplets were detected at this temperature. This might be due to the fact that the droplets of the pressure-swirl spray were smaller in diameter in comparison to the three-hole spray. Over $60 \%$ of the droplets in the pressure-swirl spray measured between less than 20 microns $100 \mathrm{~mm}$ from the injection point. Therefore these droplets were more likely to be entrained in the flow passing through the channels of the mixer and had a higher probability of avoiding contact with the channel walls resulting in an increased likelihood of downstream spray. However, this minor amount of spray still resulted in the presence small deposits on the rear window.

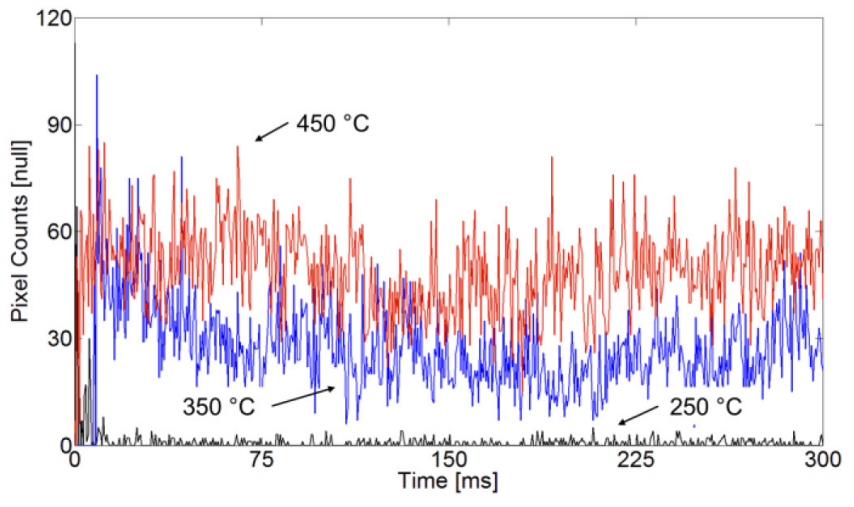

Figure 25. Quantitative analysis of high-speed imaging of spray discharging from substrate mixer with pressure-swirl injector at a dosing rate $=1500 \mathrm{~g} / \mathrm{hr}$

The effect of increasing dosing rate on the amount of spray observed downstream of the substrate at EC3 is shown in Figure 26. As seen with the other injector, spray decreased with an increase in dosing rate.

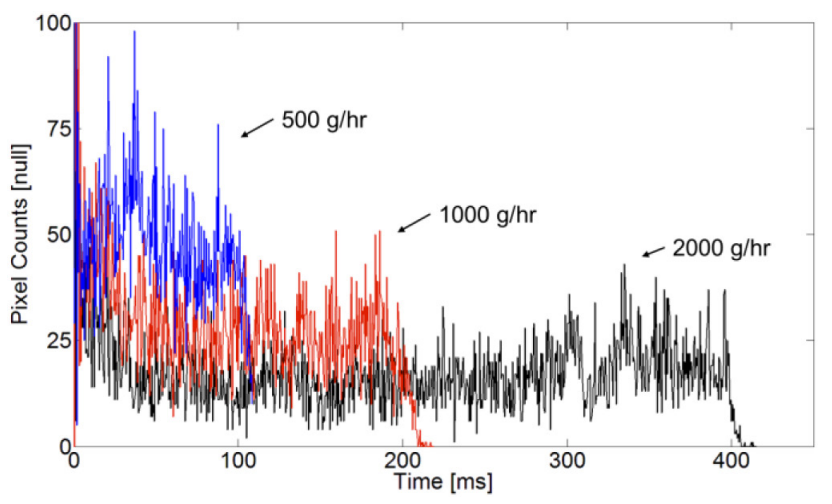

Figure 26. Quantitative analysis of high-speed imaging of spray discharging from substrate mixer with pressure-swirl injector at EC3 at 3 dosing rates 


\section{Conclusions}

An optical investigation into the interactions between two different AdBlue sprays and a high-surface area mixing device based on a 400 cpsi ceramic cordierite substrate has been carried out on a hot exhaust flow test bench under exhaust flow rates and temperatures typical of a HD diesel engine. The sprays of two injectors have been studied and measured in both ambient conditions and a heated cross-flow to develop a detailed understanding on their behaviours and characteristics.

Imaging inside the mixer tube over a sustained period of dosing with the two different injection systems has revealed the importance of correctly coupling the characteristics of the injector spray and a mixing device. The substrate mixer provided a very high-surface area through which heat could be extracted from the convecting exhaust flow and transferred into the impacting AdBlue spray. The pressureswirl injector generated a spray with a cone angle which enabled good coverage on the front of the substrate mixer. Within this solid-cone of spray, droplets with diameters no greater than 100 microns were well distributed and therefore the entire area of the substrate mixer was uniformly utilised by the spray. As a result, the formation of liquid films was generally avoided and deposit formation minimised even at high dosing rates in comparison to the two-stage mixer. This injector and mixer partnership has been demonstrated to raise the dosing limits without forming deposits which should result in NOx conversion efficiency gains.

However, the high-surface area mixer only delivered this improvement with the correct spray type. When using the three-hole injector, which produced much larger droplets up to 395 microns in size, concentrated in three jets of fluid, the available surface area of the substrate mixer could not be exploited. Instead, the spray jets resulted in liquid saturation of the channels. The saturation led to the formation of deposit rings on the rear face of the substrate at several of the conditions tested along with spitting of urea in solution onto downstream surfaces where deposits formed. In general, the substrate mixer offered little to no improvement in reducing deposits compared to the two-stage mixer when the three-hole injector was used, and in some cases actually performed worse.

The extruded profile of the substrate mixer did present the problem of allowing some of the injected spray to pass directly through the substrate resulting in the formation of small deposits at the site where spray impaction occurred downstream. The amount of spray which passed through was related to gas, and therefore substrate wall, temperature. It was shown that at $250{ }^{\circ} \mathrm{C}$ the substrate mixer was able to absorb nearly all of the spray which could be advantageous to controlling deposit formation. However as temperature increased, either through a direct increase in exhaust temperature or indirectly through reduced cooling at lower dosing rates, the amount of spray which passed through the substrate mixer increased.

\section{References}

1. Stanton, D., Charlton, S., and Vajapeyazula, P., "Diesel Engine Technologies Enabling Powertrain Optimization to Meet U.S. Greenhouse Gas Emissions," SAE Int. J. Engines 6(3):17571770, 2013, doi:10.4271/2013-24-0094.
2. Ohrnberger, T., Becker, C., and Doehring, C., "Assessment of Tier 4 Final Aftertreatment Strategies," SAE Technical Paper 2012-01-1953, 2012, doi:10.4271/2012-01-1953.

3. Johnson, T., "Vehicular Emissions in Review," SAE Int. J. Engines 5(2):216-234, 2012, doi:10.4271/2012-01-0368.

4. Zheng, G., Fila, A., Kotrba, A., and Floyd, R., "Investigation of Urea Deposits in Urea SCR Systems for Medium and Heavy Duty Trucks," SAE Technical Paper 2010-01-1941, 2010, doi:10.4271/2010-01-1941.

5. Seo, J., "Aftertreatment Package Design for SCR Performance Optimization," SAE Technical Paper 2011-01-1135, 2011, doi:10.4271/2011-01-1135.

6. Munnannur, A., Chiruta, M., and Liu, Z., "Thermal and Fluid Dynamic Considerations in Aftertreatment System Design for SCR Solid Deposit Mitigation," SAE Technical Paper 2012-011287, 2012, doi: 10.4271/2012-01-1287.

7. Smith, H., Lauer, T., Mayer, M., and Pierson, S., "Optical and Numerical Investigations on the Mechanisms of Deposit Formation in SCR Systems," SAE Int. J. Fuels Lubr. 7(2):525542, 2014, doi:10.4271/2014-01-1563.

8. De Rudder, K., Chauvin, C. Close coupled DOC-mixer-SCR for Tier 4 final. AVL International Commercial Powertrain Conference. 2013

9. Zheng, G., Gardner, T., Kotrba, A., Golin, M. et al., "Development of Urea SCR Systems for Large Diesel Engines," SAE Technical Paper 2011-01-2204, 2011, doi:10.4271/201101-2204.

10. Lundstrom, A., Andersson, B., Olsson, L. Urea thermolysis studied under flow reactor conditions using DCS and FTIR. Chemical Engineering Journal (150) 544-550. 2009. doi:10.1016/j.cej.2009.03.044.

11. Schaber, P., Colson. J., Higgins, S., Thielen, D., et al., Thermal decomposition (pyrolysis) of urea in an open reaction vessel. Thermochimica Acta (424) 131-142. 2004. doi:10.1016/j. tca.2004.05.018.

12. Fang, H., DaCosta, H. Urea thermolysis and NOx reduction with and without SCR catalysts. Applied Catalysis B: Environmental (46) 17-34. 2003 doi:10.1016/S0926-3373(03)00177-2.

\section{Contact Information}

Tom Lockyer

Wolfson School of Mechanical \& Manufacturing Engineering

Loughborough University

Loughborough, Leics, LE11 2HH, UK

t.lockyer@lboro.ac.uk

\section{Acknowledgments}

The authors would like to thank the Energy Technologies Institute (ETI) for commissioning and funding the project on which this work is based. All of the experimental data was gathered at Loughborough University with thanks to Mark Capers, David Britton and Robert Temple for their technical assistance and support during the construction of the test bed facility. Caterpillar and Johnson Matthey PLC for their advice and support, notably Mark Kennedy, Dave Heaton, Andrew Keen, Ron Silver and Michael Nash. Thanks to the Engineering and Physical Sciences Research Council (EPSRC) for providing additional funding. 


\section{Definitions/Abbreviations}

AdBlue - A fluid consisting of $32.5 \%$ urea by mass in ultra-pure water

ASC - Ammonia Slip Catalyst

CPSI - Cells Per Square Inch

DPF - Diesel Particulate Filter

DSLR - Digital Single-Lens Reflex
HD - Heavy-Duty

MFM - Mass Flow Meter

NOx - Nitrogen Oxides

PDI - Phase Doppler Interferometry

SCR - Selective Catalytic Reduction

SMD - Sauter Mean Diameter

The Engineering Meetings Board has approved this paper for publication. It has successfully completed SAE's peer review process under the supervision of the session organizer. The process requires a minimum of three (3) reviews by industry experts.

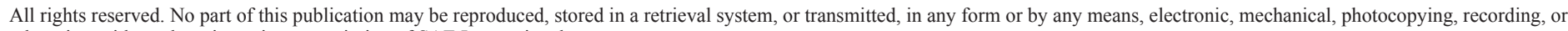
otherwise, without the prior written permission of SAE International.

Positions and opinions advanced in this paper are those of the author(s) and not necessarily those of SAE International. The author is solely responsible for the content of the paper.

ISSN 0148-7191

http://papers.sae.org/2015-01-1039 